\title{
Water in Oil W/O Pickering Emulsion Encapsulated in Oil in Water O/W Emulsion: A Double Emulsion for Poorly Soluble Drugs
}

\author{
Sidy Mouhamed Dieng ${ }^{1,2,3, *}$, Louis Augustin Diaga Diouf ${ }^{2}$, Alphonse Rodrigue Djiboune $^{2}$, \\ Papa Mady $\mathrm{Sy}^{2}$, Mamadou Soumboundou ${ }^{1}$, Djibril Kebe ${ }^{2}$, Gora Mbaye ${ }^{2}$, Oumar Thioune ${ }^{3}$, \\ Mounibe Diarra ${ }^{1, *}$ \\ ${ }^{1}$ Department of Pharmacy, Laboratory of Galenic Pharmacy \& Industrial Pharmacy and Pharmaceutical Physics and Biophysics, Health \\ Training and Research Unit, Thies University, Thies, Senegal \\ ${ }^{2}$ Department of Pharmacy, Laboratory of Pharmaceutical Physics and Biophysics, Faculty of Medicine, Pharmacy and Odontology, Cheikh \\ Anta Diop University, Dakar, Senegal \\ ${ }^{3}$ Department of Pharmacy, Laboratory of Galenic Pharmacy, Faculty of Medicine, Pharmacy and Odontology, Cheikh Anta Diop University, \\ Dakar, Senegal
}

Email address:

sidym.dieng@univ-thies.sn (S. M. Dieng), mounibe.diarra@ucad.edu.sn (M. Diarra)

${ }^{*}$ Corresponding author

\section{To cite this article:}

Sidy Mouhamed Dieng, Louis Augustin Diaga Diouf, Alphonse Rodrigue Djiboune, Papa Mady Sy, Mamadou Soumboundou, Djibril Kebe, Gora Mbaye, Oumar Thioune, Mounibe Diarra. Water in Oil W/O Pickering Emulsion Encapsulated in Oil in Water O/W Emulsion: A Double Emulsion for Poorly Soluble Drugs. Pharmaceutical Science and Technology. Vol. 4, No. 2, 2020, pp. 25-30.

doi: $10.11648 /$ j.pst.20200402.11

Received: October 30, 2020; Accepted: November 21, 2020; Published: November 30, 2020

\begin{abstract}
There are two problems that hinder the use of double emulsions in pharmacies: large-scale equipment not available for one-step emulsification and obtaining a double emulsion and limited ingredients available to replace the tensionactive agents as primary emulsifier because these surfactants are toxic. To overcome these difficulties, a two-stage emulsification strategy has been developed, first generating a water-in-oil Pickering emulsion stabilized by magnesium oxide particles and then the double $\mathrm{W} / \mathrm{O} / \mathrm{W}$ emulsion, thereby reducing significantly the amount of voltage-active. Pickering emulsions are surfactant-free emulsions, stabilized by colloidal particles. These systems are experiencing renewed interest on the one hand, because it is preferable to limit the use of synthetic surfactants for ecological reasons, and on the other hand, because the functionalization of particles has undergone recent advances. It is possible to make very simple calibrated emulsions of controlled size, exploiting a phenomenon called "limited coalescence". The Bancroft rule served as a model for the formulation. The emulsification was carried out using a rotor stator mixer. The stability of these emulsions has been studied using several parameters $(\mathrm{pH}$, conductivity, droplet size, dye test). The dye test and the conductivity measurement confirmed the $\mathrm{W} / \mathrm{O}$ nature of the emulsion and $\mathrm{W} / \mathrm{O} / \mathrm{W}$ nature of the double emulsion. This study showed that we were able to develop a saturated double $\mathrm{W} / \mathrm{O} / \mathrm{W}$ emulsion.
\end{abstract}

Keywords: Pickering, Double Emulsion, Magnesium Oxide

\section{Introduction}

Multiple emulsions are emulsions of emulsions. In other words the stabilization of internal drops in drops of larger diameters. These internal emulsions can be Pickering emulsions. Pickering emulsions are dispersions of two immiscible liquids stabilized by solid particles. They are generally made up of three components: a phase, an oily phase and the stabilizing particles. The effect of stabilization of emulsions by fine particles has been known for about a century. These emulsions are called the "Pickering emulsion" after one of the first researchers to describe this type of stabilization in 1907. He established that particles can act as 
surfactants and stabilize oil in water or water in oil emulsions. However, the first description of this phenomenon is due to Ramsden in 1903; his article is cited by Pickering [1]. This concept of emulsion stabilized by solid particles is experiencing a renewed interest these days given the many advantages it offers: good stability, environmental protection, user safety, varieties of particles etc... At the fundamental level, emulsions raise questions relating to their preparation (emulsification), their lifespan (mechanism of kinetics of destruction), their flow properties (rheology, elasticity of concentrated emulsions), etc. these questions have been addressed in the presence of surfactants or proteins but rarely in the presence of solid particles [2-6].

A double emulsion is a simple type of multiple emulsion [7, 8]. The most studied double emulsion is the water-oil-water $(\mathrm{W} / \mathrm{O} / \mathrm{W})$ emulsion, in which the oil droplets in a continuous water system containing smaller water droplets [9-12]. The double emulsions have aroused considerable interest because of their potential application in various fields, notably pharmacy, syntheses of materials, the cosmetic industry and the food industry. [13-16]. Due to their compartmentalized internal structure, double emulsions are an ideal distribution system for the encapsulation of two hydrophilic and reservoirs of hydrophobic active substances with different polarity. Robust double emulsion formulations with long-term physical stability are difficult to obtain due to coalescence or diffusion of internal water droplets to the external aqueous phase by coalescence. Thus stabilization strategies, encapsulation techniques and applications of double emulsions in recent years have shown that for fully commercial exploitation of double emulsions must be stable. Conventional approaches to generate double $\mathrm{W} / \mathrm{O} / \mathrm{W}$ emulsions are based on a two-step emulsification process using a combination of two distinctive surfactants. Traditional double emulsions stabilized by low molecular weight surfactants are both thermodynamically and kinetically unstable, which in effect presents the active voltage exchange between the internal phase droplets. In this study to overcome the instability inherent in double emulsions stabilized by surfactants, the colloidal particles stabilizing emulsions received a lot of attention. For double emulsions, the Pickering emulsions can be extremely robust because the colloidal particles form a mechanical barrier which reduces the instability of the water droplets which are encapsulated in the oily droplet, thus improving the overall stability of the system. Additionally, it could also lead to a considerable reduction in the amounts of surfactant used. The general objective of this work was to produce a double Pickering $\mathrm{W} / \mathrm{O} / \mathrm{W}$ emulsion stabilized by particles of magnesium oxide $(\mathrm{MgO})$ in an emulsion stabilized by a surfactant.

\section{Experimental Section}

\subsection{Materials}

The material used for the formulation and characterization of Pickering emulsions is as follows: $\mathrm{pH}$ meter CG820 SCHOTT GERATE, Ultra Turax (KRIEGER TEZ) Rotor-
Stator, SCHOTT GERATE conductivity meter, ZEISS optical microscope, BBT KRAUSS optical microscope.

\subsection{Methods}

\subsubsection{Formulation of Pickering Simple-emulsion}

One of the most important properties and characteristics during formulation is the direction of the emulsion formed. The formulator has always been faced with the problem of predicting the type of emulsion formed when a water-oilparticle system is mixed and stirred.

The Bancroft rule, which states that the direction of the emulsion depends on the medium where the particles are initially introduced, has served as a model for the preparation of our emulsions. The formulation was carried out at $25^{\circ} \mathrm{C}$. and comprises several phases. After mixing the quantity of well-weighed particles in the oily phase containing petroleum jelly, we added the distilled water dropwise using a graduated burette, stirring at a speed of $1000 \mathrm{rpm}$ on an agitator. After stirring we proceeded to the actual emulsion by placing the mixture on the ultraturax which is rotated at a speed of 5000 rpm. This process allowed us to produce emulsions of different proportions with. In the following tables we show the different proportions of aqueous and oily phases used. The percentage of particles used was varied from 1 to $10 \%$. Then the emulsions prepared were put in Falcon tubes for the observation of the stability and the physico-chemical study.

Table 1. Composition of the different formulations with 0,5 $\mathrm{g}$ of Vaseline.

\begin{tabular}{llllll}
\hline TUBES & T1 & T2 & T3 & T4 & T5 \\
\hline Volume of water $(\mathrm{ml})$ & 15 & 15 & 15 & 15 & 15 \\
Volume of oil $(\mathrm{ml})$ & 7 & 7 & 7 & 7 & 7 \\
\% particule & 0 & 1 & 3 & 4 & 5 \\
Particles mass $(\mathrm{g})$ & 0 & 0,07 & 0,21 & 0,28 & 0,35 \\
Vaseline mass $(\mathrm{g})$ & 0,5 & 0,5 & 0,5 & 0,5 & 0,5 \\
\hline
\end{tabular}

Table 2. Composition of the different formulations with 0,25 $\mathrm{g}$ of Vaseline.

\begin{tabular}{llllll}
\hline TUBES & T1 & T2 & T3 & T4 & T5 \\
\hline Volume of water $(\mathrm{ml})$ & 15 & 15 & 15 & 15 & 15 \\
Volume of oil $(\mathrm{ml})$ & 7 & 7 & 7 & 7 & 7 \\
\%particule & 0 & 1 & 2 & 3 & 5 \\
Particles mass $(\mathrm{g})$ & 0,035 & 0,07 & 0,14 & 0,21 & 0,35 \\
Vaseline mass $(\mathrm{g})$ & 0,15 & 0,15 & 0,15 & 0,15 & 0,15 \\
\hline
\end{tabular}

Table 3. Composition of the different formulations with $0,15 \mathrm{~g}$ of Vaseline.

\begin{tabular}{llllll}
\hline TUBES & T1 & T2 & T3 & T4 & T5 \\
\hline Volume of water (ml) & 10 & 10 & 10 & 10 & 10 \\
Volume of oil (ml) & 10 & 10 & 10 & 10 & 10 \\
\%particule & 0 & 1 & 2 & 3 & 5 \\
Particles mass (g) & 0,1 & 0,2 & 0,3 & 0,4 & 0,5 \\
Vaseline mass (g) & 0,25 & 0,25 & 0,25 & 0,25 & 0,25 \\
\hline
\end{tabular}

\subsubsection{Formulations of Double-emulsions}

For the rest of the work we chose the T5 tube containing $0.15 \mathrm{~g}$ of petroleum jelly, $15 \mathrm{ml}$ of water, $7 \mathrm{ml}$ of oil and $5 \%$ of particles for the preparation of the double emulsion. This tube was chosen because it does not show any instability phenomenon after several days of storage protected from light.

This time distilled water was used as the aqueous phase and the stabilization is carried out using Cremophor ${ }^{\mathbb{R}}$ ELP. 
We first prepared our Cremophor ${ }^{\circledR}$ ELP solution at a different percentage. The emulsification is carried out by adding the single Pickering emulsion drop by drop. The emulsification is carried out first at a speed of $1000 \mathrm{rpm}$ and then, for good homogenization, it is stirred at a speed of $3000 \mathrm{rpm}$ for 3 minutes. These double emulsions were then stored in Falcon tubes, protected from light.

Table 4. Preparation of the Cremophor ${ }^{\circledR}$ ELP solution.

\begin{tabular}{|c|c|c|c|c|c|c|c|c|c|c|}
\hline \% Cremophor ${ }^{\circledR}$ ELP & 1 & & 2 & & 3 & & 4 & & 5 & \\
\hline $\begin{array}{l}\text { Volume of simple } \\
\text { émulsion }(\mathrm{ml})\end{array}$ & 5 & 10 & 5 & 10 & 5 & 10 & 5 & 10 & 5 & 10 \\
\hline
\end{tabular}

\subsection{Emulsion and Double Emulsion Characterization}

\subsubsection{Macroscopic Examination}

The emulsions are left to stand in the dark and at room temperature in $15 \mathrm{ml}$ conical tubes fitted with lids. This visual inspection highlights certain phenomena of instability such as sedimentation, flocculation and coalescence.

\subsection{2. pH Determination}

The determination of the $\mathrm{pH}$ of the solutions is based on the measurement of the potential between two electrodes immersed in a solution rich in $\mathrm{H}+$ ions

After calibrating the $\mathrm{pH}$ meter with solutions of known $\mathrm{pH}$, the electrode is dipped into a $15 \mathrm{ml}$ conical tube containing the preparation to be studied. Like conductivity, care should be taken to immerse the electrodes to the level of the emulsified phase for tubes with sedimentation. The reading is made a few minutes after the insertion of the electrode.

\subsubsection{Conductivity Measurement}

It is based on the measurement of the electrical resistance of a solution located between 2 plates covered with platinum black. Depending on the concentration of ions present, the solution will have a greater or lesser conductivity. The conductimetry cell is introduced into a $15 \mathrm{ml}$ tube fitted with a screw-on lid containing the preparation to be studied. In the presence of a conductive preparation, the conductivity meter displays a value corresponding to the conductivity and expressed in Siemens per meter (S. m-1). In the case of tubes with sedimentation, immerse the conductive cell to the level of the emulsified fraction.

\subsubsection{Droplet Size of Pickering Emulsion and Double Emulsion}

It is based on the determination of the droplet size using the clear chamber microscope (BBT KRAUSS). It consists in putting a drop of the emulsion on a slide then placing it on the stage then observing at the $20 \mathrm{X}$ objective. A sheet of white paper is placed on the bench so as to see the image of the droplets on this sheet through the clear chamber and delineate in pencil the contours of the observed droplets. Without moving the sheet, replace the object lamp with a micrometerobjective of $1 \mathrm{~mm}$ to $1 / 100$. The development is carried out to distinguish the graduations. Take marks on the sheet in coincidence with a few graduations on the micrometric scale. The actual droplet size is calculated based on a given scale.

\section{Results}

\subsection{Formulation of Pickering Simple-emulsion and Double Emulsion}

The study of the physico-chemical parameters of the different emulsions formulated and stored in the dark at $25^{\circ} \mathrm{C}$ for 28 days allowed us to follow the evolution of the formulations as a function of time. For simple emulsions we have found that the compositions having $0.15 \mathrm{~g}$ of petrolatum, $5 \%$ of particle, $15 \mathrm{ml}$ of water and $7 \mathrm{ml}$ of oil are stable. Concerning the double emulsion we have several unstable preparations except that of the tube containing $5 \mathrm{ml}$ of aqueous phase with $2 \%$ Cremophor $^{\circledR}$ ELP and $10 \mathrm{ml}$ of simple stable emulsion.

For the double emulsion, the macroscopic examination gave us an overview of the appearance of the double emulsions.

\subsection{Characterization of Pickering Simple-emulsion and Double Emulsion}

\subsubsection{Droplet size of Pickering Emulsion and Double Emulsion}

The observation of the different samples under the light microscope showed droplets of heterogeneous sizes and the evolution of the size of the droplets as a function of the percentage of magnesium oxide is shown in Figure 1 below.

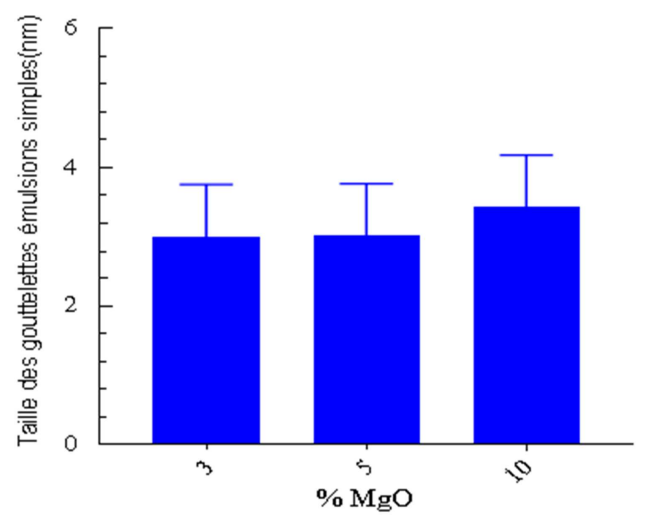

Figure 1. Size of the droplets of the simple emulsion as a function of the percentage of magnesium oxide.

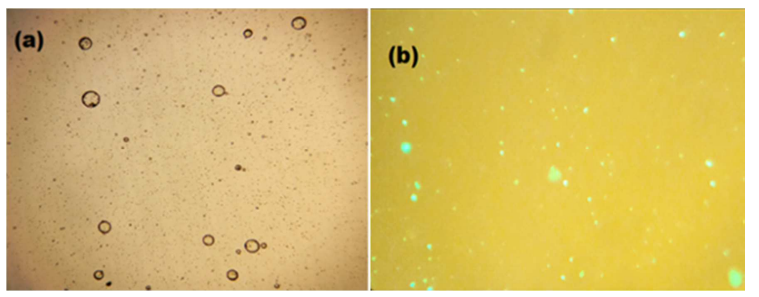

Figure 2. Microscopic examination of the droplets of the simple emulsion (a): Microscopic examination of the droplets without dye (b): Microscopic examination of the droplets with sudan red.

In Figure 3 we show the size of the droplets of the double emulsion. 


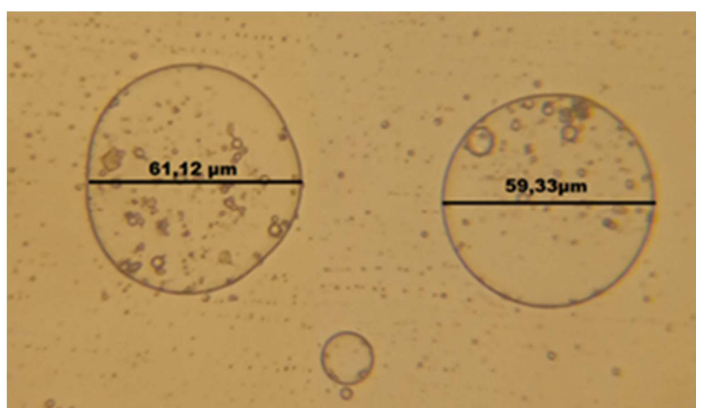

Figure 3. Size of the droplets of the double emulsion.

\subsubsection{Microscopic Examination (Dye Tests)}

The dye tests carried out each week during the 28 days of follow-up showed us emulsions with aqueous droplets of heterogeneous fluorescent sizes after staining with fluorescein.

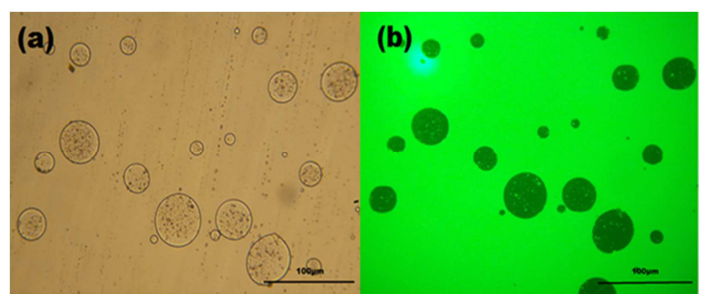

Figure 4. Microscopic examination of the droplets of the double emulsion (a): Microscopic examination of the droplets without dye (b): Microscopic examination of the droplets with Sudan red.

\subsection{3. pH Determination}

Figure 5 below is shown the evolution of the $\mathrm{pH}$ of our Pickering emulsions on day 1 , day 7 , day 14 , day 21 , and day 28. In Figure 6 below is shown the evolution of the $\mathrm{pH}$ of our emulsions on day 1 , day 7 , day 14 , day 21 , and day 28 .

\subsubsection{Conductivity Measurement}

Determining the direction of our emulsions by measuring the conductivity on the following days: $\mathrm{d} 1, \mathrm{~d} 7, \mathrm{~d} 14, \mathrm{~d} 21, \mathrm{~d} 28$ gave the values of zero conductivity. In Figure 7 below is shown the conductivity of our double emulsions on $d 1, d 7$, $\mathrm{d} 14, \mathrm{~d} 21$, and $\mathrm{d} 28$.



Figure 5. Evolution of the pH of simple emulsions as a function of time.

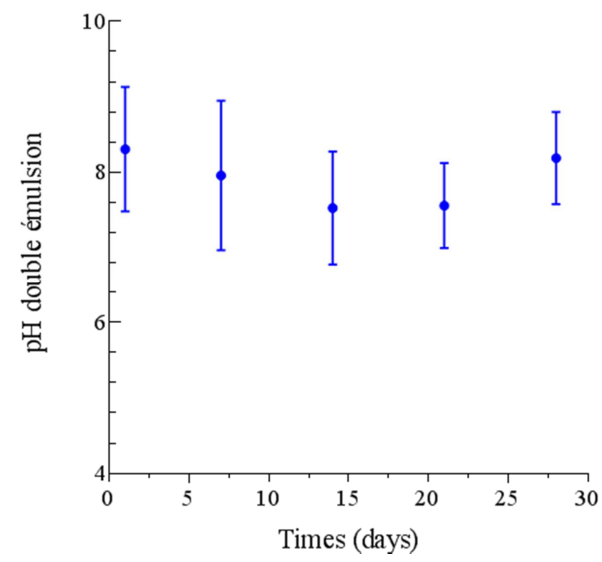

Figure 6. Evolution of the pH of the simple emulsion as a function of time.

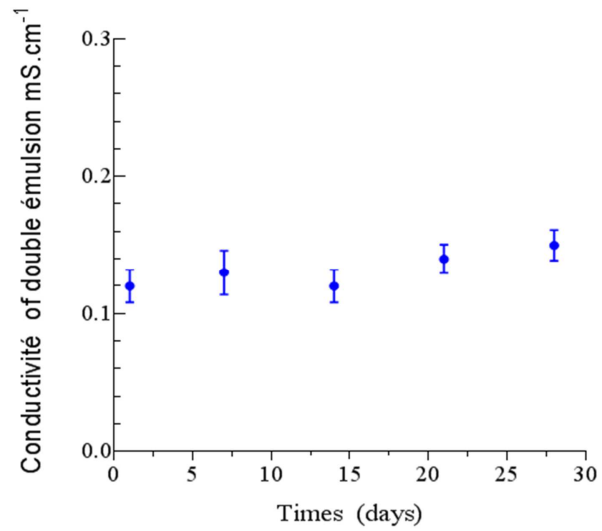

Figure 7. Evolution of the conductivity of the double emulsion as a function of time.

\section{Discussion}

The objective of this work is the formulation and the physico-chemical characterization of a double $\mathrm{W} / \mathrm{O} / \mathrm{W}$ emulsion which has been prepared in two stages. The first step consisted in preparing a W/O type emulsion stabilized by $\mathrm{MgO}$ particles. The second step was to prepare a $\mathrm{W} / \mathrm{O} / \mathrm{W}$ emulsion. The latter is stabilized by Crémophor ${ }^{\circ}$ ELP which is a nonionic surfactant. To carry out the emulsifications we used an ultra-turax mixer. For the study of stability and characterization, several parameters were studied (macroscopic examination, microscopic examination, measurement of droplet size, measurement of $\mathrm{pH}$, measurement of conductivity, etc.). This approach is interesting because it allows biencapsulation [17, 18]. Macroscopic observation of simple emulsions shows that the preparations containing $3 \%, 5 \%$ and $10 \%$ of $\mathrm{MgO}$ particles with $15 \mathrm{ml}$ of water and $7 \mathrm{ml}$ of oil are homogeneous, without creaming or sedimentation during visual inspection. Throughout the follow-up period. Concerning the double emulsion we have the preparation containing $5 \mathrm{ml}$ of aqueous phase with $2 \%$ of chremophor ELP and $10 \mathrm{ml}$ of simple emulsion with $5 \%$ of $\mathrm{MgO}$ which is stable. However, it should be borne in mind that the absence of change perceived with the naked eye does not prejudge the stability of the emulsion. Indeed, macroscopic observation does not allow to see droplets smaller than 50um. The other 
formulations containing different percentages of particles, different volumes of aqueous and oily phase have shown phase separation which can be observed with the naked eye.

The phenomenon of creaming, considered normal, is generally the first to appear. It is much easier to observe when the tubes are kept in the vertical position (Bolte test). Indeed according to the stock-Einstein law, defining the friction force of a fluid on a sphere moving within the said liquid, the creaming (or sedimentation) speed is directly linked by the mathematical law:

$$
\vec{F}=-6 \eta r \vec{v}
$$

$\vec{F}=$ force acting on the droplets

This law is used to calculate the rate of sedimentation of droplets. It can also be written in the form of:

$$
v=\frac{2 r^{2} g\left(D_{1}-D_{2}\right)}{9 \eta}
$$

$\mathrm{v}=$ sedimentation rate $(\mathrm{m} / \mathrm{s}) \quad \mathrm{r}=$ droplet radius $(\mu \mathrm{m})$ $\mathrm{g}=$ acceleration due to Earth's gravity $(\mathrm{m} / \mathrm{s} 2)(\mathrm{g}=9.807 \mathrm{~m} / \mathrm{s} 2)$ $\mathrm{D} 1 ; \mathrm{D} 2=$ respective densities of the dispersed phase and the continuous phase $\eta=$ viscosity of the continuous phase in centpoise $(\mathrm{cPo})$

Indeed, the size of the particles plays a preponderant role in the stability of the emulsions; thus a 100um diameter globule rises $10 \mathrm{~cm}$ in water in just 3 minutes, while it takes 5 um globules of 10um diameter and 20 days takes globules of 1 um diameter to climb the same distance $[19,20]$. The size of the droplets also plays an important role in the stability of the emulsions. This is one of the variables that influences the rate of sedimentation described by Stockes' law. The amount of particles used plays an important role in the stability of Pickering emulsions. Indeed, by increasing the amount of $\mathrm{MgO}$ in the preparations, better stability is obtained. This is explained by the fact that when the latter is in excess in the emulsion, a greater quantity is adsorbed at the water-oil interface and forms an interface thus promoting greater resistance. On the other hand, the quantity of particle is related to the size of the droplets, in fact the samples containing less particles have a larger diameter than those of samples containing a larger quantity of particles.

This confirms the hypothesis that the size of the droplets varies in opposite directions with the quantity of $\mathrm{MgO}$ particles in the samples. This relation between the diameter and the quantity of particle is illustrated by the following formula.

$$
\mathrm{D}=\frac{6 \emptyset_{\mathrm{V}} \mathrm{V}}{\mathrm{A}}
$$

$\mathrm{D}=$ diameter of the droplets

$\mathrm{A} / \mathrm{V}$ is the interracial air per unit of volume

$\emptyset_{\mathrm{V}}$ is the fraction of the dispersed phase

However, other studies have shown that the excess of nonadsorbed particles contributes to the stabilization of emulsions by the formation of a three-dimensional network of flocculated particles. This improves stability by interfering with mutual contact of the droplets [21]. Study of the conductivity of the single emulsion showed zero values confirming the $\mathrm{W} / \mathrm{O}$ nature of the Pickering emulsion and $\mathrm{W} / \mathrm{O} / \mathrm{W}$ of the double emulsion. The conductivity of an emulsion being directly linked to that of the external phase and aqueous solvents better conductors than oily solvents, the zero conductivity of our formulations confirms their W/O nature. Stabilité Indeed, the presence of electrolytes in the aqueous phase makes it have a high conductivity. On the other hand, an oily phase by its apolar nature is characterized by its very low capacity and a constant value of conductivity over time is a determining criterion of stability [22]. That of the double emulsion is not zero during the storage period. This value is in agreement with that described in the literature. In most cases, water, unlike oil, contains electrolytes. The conductivity of the aqueous phase is 100 to 1000 times higher than that of oil.

The value of the conductivity of an emulsion depends on its external phase, so it is relatively easy to determine whether the emulsion is of the $\mathrm{W} / \mathrm{O}$ or $\mathrm{O} / \mathrm{W}$ type. The conductivity of an emulsion is directly related to the conductivity of the external phase and its volume fraction. Thus, as a first approximation we can use the following linear relation:

$$
\mathrm{K}_{\mathrm{em}}=\mathrm{F}_{\mathrm{w}} \cdot \mathrm{K}_{\mathrm{ext}}
$$

The external phase can also be of crucial importance in the interpretation of the phenomena observed for emulsions, in particular for detecting phase inversion during an emulsification process.

The $\mathrm{pH}$ values are basic. And the latter lead to an increase in the surface potential of the aqueous globules, therefore an increase in the inter-particle electrostatic repulsion forces favorable to better stability. This result was noted during studies made with W/O emulsions stabilized by hydrophobic silicas [23]. The $\mathrm{MgO}$ used is a powder with a strongly basic character causing the basicity of our emulsions, giving them better stability. Yang and his collaborators have shown that a basic improves the stability of emulsions. Indeed, for low $\mathrm{pH}$, the droplets are large and not flocculated [24].

\section{Conclusion}

In this study, a water in oil in water emulsion was successfully formulated. We made a formulation in two stages. First a Pickering water-in-oil emulsion stabilized by $\mathrm{MgO}$ magnesium oxide particles was prepared, then the second oil-in-water emulsion stabilized by Cremophor ELP which is an active nonionic voltage. We have shown that the $\mathrm{MgO}$ particles provide satisfactory stabilization of the oil-water interface. We have also shown that double emulsions are stable and have a relatively homogeneous size distribution, high water droplet encapsulation as well as good storage stability. In addition, the internal water droplets stabilized by Pickering effect increases the stability of the double emulsion. This implies that this system can be used to stabilize and simultaneously deliver hydrophilic and hydrophobic PA. This study shows that double emulsions have promising potential for pharmaceutical application. 


\section{Acknowledgements}

The authors declare no conflicts of interest.

\section{References}

[1] Pickering SU. CXCVI.-Emulsions. J Chem Soc Trans. 1907; 91: 2001-21.

[2] Abismaïl B, Canselier JP, Wilhelm AM, Delmas H, Gourdon C. Emulsification by ultrasound: drop size distribution and stability. Ultrason Sonochem. 1999; 6: 75-83.

[3] Dieng SM, Soumboundou M, Sy PM, MohamedWane T, Djiboune AR, Diouf LAD, et al. Formulation and Evaluation of Water/Oil Pickering Emulsion Stabilized by Magnesium Oxide Particles Containing Paracetamol in the Internal Phase. ARC J Pharm Sci. ARC Journals; 2019; 5: 34-42.

[4] Frelichowska J, Bolzinger M-A, Chevalier Y. Effects of solid particle content on properties of o/w Pickering emulsions. J Colloid Interface Sci. 2010; 351: 348-56.

[5] Kim J-H, Kim S-E, Kyong K-Y, Lee E-J, Cho W-G, Yoon MS. Effect of aqueous phase composition on the stability of a silica-stabilized water-in-oil emulsion. J Soc Cosmet Sci Korea. 2004; 30.

[6] Linke C, Drusch S. Pickering emulsions in foods opportunities and limitations. Crit Rev Food Sci Nutr. 2018; 58: 1971-85.

[7] Altuntas OY, Sumnu G, Sahin S. Preparation and characterization of $\mathrm{W} / \mathrm{O} / \mathrm{W}$ type double emulsion containing PGPR-lecithin mixture as lipophilic surfactant. J Dispers Sci Technol. Taylor \& Francis; 2017; 38: 486-93.

[8] Spyropoulos F, Duffus LJ, Smith P, Norton IT. Impact of Pickering Intervention on the Stability of W1/O/W2 Double Emulsions of Relevance to Foods. Langmuir. American Chemical Society; 2019; 35: 15137-50.

[9] Devanthi PVP, Linforth R, El Kadri H, Gkatzionis K. Waterin-oil-in-water double emulsion for the delivery of starter cultures in reduced-salt moromi fermentation of soy sauce. Food Chem. 2018; 257: 243-51.

[10] Devanthi PVP, El Kadri H, Bowden A, Spyropoulos F, Gkatzionis K. Segregation of Tetragenococcus halophilus and Zygosaccharomyces rouxii using $\mathrm{W} 1 / \mathrm{O} / \mathrm{W} 2$ double emulsion for use in mixed culture fermentation. Food Res Int. 2018; 105: 333-43.

[11] Diouf LA, Mbaye G, Ndiaye A, Diarra M. Peanut oil based W1/o/W2 multiple emulsions for oral administration of insulin | International Journal of Current Research [Internet]. 2015. Available from: https: //www.journalcra.com/article/peanutoil-based-w1 low2-multiple-emulsions-oral-administrationinsulin.

[12] Zhu Q, Qiu S, Zhang H, Cheng Y, Yin L. Physical stability, microstructure and micro-rheological properties of water-inoil-in-water $(\mathrm{W} / \mathrm{O} / \mathrm{W})$ emulsions stabilized by porcine gelatin. Food Chem. 2018; 253: 63-70.

[13] Balcão VM, Glasser CA, Chaud MV, Vila MMDC. Chapter 6 - Water-in-Oil-in-Water Nanoencapsulation Systems. In: Sagis LMC, editor. Microencapsul Microspheres Food Appl [Internet]. San Diego: Academic Press; 2015 [cited 2020 Jun 26]. p. 95-129. Available from:

http://www.sciencedirect.com/science/article/pii/B978012800 350300008X.

[14] Blanco ME, Gallo JAQ, Arias KSE, Islas RP. Colorimetry Technique as a Tool for Determining Release Kinetics and Mass Transfer Parameters of Anthocyanins Encapsulated in W1/O/W2 Double Emulsions. Int J Food Eng. De Gruyter; 2016; 12: 615-24.

[15] Ding S, Serra CA, Vandamme TF, Yu W, Anton N. Double emulsions prepared by two-step emulsification: History, state-ofthe-art and perspective. J Controlled Release. 2019; 295: 31-49.

[16] Eslami P, Davarpanah L, Vahabzadeh F. Encapsulating role of $\beta$-cyclodextrin in formation of pickering water-in-oil-in-water (W1/O/W2) double emulsions containing Lactobacillus dellbrueckii. Food Hydrocoll. 2017; 64: 133-48.

[17] Kini GC, Biswal SL, Wong MS. Non-LBL Assembly and Encapsulation Uses of Nanoparticle-Shelled Hollow Spheres. 2010 .

[18] Theron F. Conception et mise en œuvre d'un procédé intensifié continu de microencapsulation par polycondensation interfaciale [Internet] [phd]. 2009 [cited 2019 Oct 14]. Available from: http://ethesis.inptoulouse.fr/archive/00001225/.

[19] Begbeg A. Importance des considérations environnementales dans l'étude des performances des additifs utilises dans les fluides de forage [Internet] [Thesis]. 2008 [cited 2019 Oct 14]. Available from: http://192.168.100.2: 8080//handle/123456789/1106.

[20] Yan Y, Masliyah JH. Solids-stabilized oil-in-water emulsions: Scavenging of emulsion droplets by fresh oil addition. Colloids Surf Physicochem Eng Asp. 1993; 75: 123-32.

[21] Fouilloux S. Nanoparticules et microfluidique pour un système modèle d'émulsions de Pickering. Etude des mécanismes de stabilisation et déstabilisation. 2011; 248.

[22] Vignati E, Piazza R, Lockhart TP. Pickering Emulsions: Interfacial Tension, Colloidal Layer Morphology, and Trapped-Particle Motion. Langmuir. 2003; 19: 6650-6.

[23] Tarimala S, Dai LL. Structure of Microparticles in SolidStabilized Emulsions. Langmuir. 2004; 20: 3492-4.

[24] Yang F, Niu Q, Lan Q, Sun D. Effect of dispersion pH on the formation and stability of Pickering emulsions stabilized by layered double hydroxides particles. J Colloid Interface Sci. 2007; 306: 285-95. 